\title{
PELATIHAN PENGELASAN SMAW SERTA KESELAMATAN KESEHATAN KERJA DAN PENCEGAHAN KECELAKAAN KERJA PADA PENGELASAN BAGI USAHA KECIL MENENGAH SE KOTA BANJARMASIN
}

\author{
Anhar Khalid ${ }^{1}$, Darmansyah ${ }^{2}$, Akmal Barry ${ }^{3}$, Saberani $^{4}$, Yusuf Rizal Fauzi ${ }^{5}$ \\ Jurusan Teknik Mesin, Politeknik Negeri Banjarmasin, Kalimantan Selatan. \\ Jl. Brig Jend. Hasan Basri, Pangeran, Kec. Banjarmasin Utara, Kota Banjarmasin, Kalimantan \\ Selatan $70123^{1,2,3,4,5}$ \\ anharkhalid@poliban.ac.id $^{1}$ \\ darman_poliban@yahoo.com ${ }^{2}$ \\ akmal.berry@yahoo.com ${ }^{3}$ \\ saberani@poliban.ac.id ${ }^{4}$ \\ yusuf.rizal.fauzi@poliban.ac.id
}

\begin{abstract}
Abstrak
Pelatihan bertujuan agar peserta dapat memahami cara pengelasan SMAW dengan benar dan berperilaku pentingnya K3 dalam proses pengerjaan pengelasan, mengidentifkasi potensi bahaya di tempat kerja, melakukan pencegahan kecelakaan kerja, mengelola bahan-bahan beracun berbahaya dan penanggulangannya, menggunakan alat pelindung diri, melakukan pencegahan dan pemadaman kebakaran serta menyusun program pengendalian Keselamatan dan Kesehatan kerja di bengkel. Pelatihan ini bertempat di workshop Politeknik Negeri Banjarmasin, Kalimantan Selatan. Peserta pelatihan sebanyak 10-15 orang tukang bengkel las yang berasal dari sekitaran kota Banjarmasin dengan instruktur dosen Politeknik Negeri Banjarmasin sebanyak 3 orang dan dibantu Mahasiswa Politeknik Negeri Banjarmasin sebanyak 3 orang. Metode yang digunakan meliputi ceramah, tanya jawab, diskusi, demonstrasi dan penugasan. Hasil pelatihan menunjukkan bahwa peserta memiliki wawasan, pemahaman dan sikap bekerja yang selamat dan sehat, yang meliputi Pengertian dan Tujuan Keselamatan dan Kesehatan Kerja Identifikasi Potensi Bahaya di Tempat Kerja Faktor-faktor Penyebab Kecelakaaan Kerja Zat dan Bahan Berbahaya Pencegahan dan Pemadaman Kebakaran dan Penyusunan Program Pengendalian K3 dalam upaya peningkatan produktifitas kerja. Peserta juga mampu menyusun rencana kerja berupa makalah pengendalian bahaya di bengkel kerja masing-masing.
\end{abstract}

Kata kunci : Pelatihan Pengelasan SMAW, Keselamatan dan Kesehatan Kerja.

\begin{abstract}
The training aims to enable participants to understand how to properly welding SMAW and behave in the importance of $K 3$ in the welding process, identify potential hazards at work, prevent work accidents, manage hazardous toxic materials and overcome them, use personal protective equipment, prevent and extinguish fires and arrange work safety and health control programs in the workshop. The training took place at the Banjarmasin State Polytechnic workshop, South Kalimantan. There were 10-
\end{abstract}


15 trainees in the workshop who came from around the city of Banjarmasin, with 3 instructors from the Banjarmasin State Polytechnic and assisted by 3 Banjarmasin State Polytechnic Students. The methods used include: lectures, questions and answers, discussions, demonstrations and assignments. The results of the training show that participants have insight, understanding and working attitudes that are safe and healthy, which includes the Definition and Purposes of Occupational Safety and Health Identification of Potential Hazards at Work $K 3$ in an effort to increase work productivity. Participants are also able to draw up a work plan in the form of hazard control papers at their respective workshop.

Keyword : Training, SMAW welding, Occupational Health and Safety

\section{PENDAHULUAN}

Potensi ancaman pada proses pengelasan terhadap keselamatan dan kesehatan kerja berkenaan dengan tempat kerja atau bengkel produksi meliputi: lokasi bengkel tempat kerja berjarak sangat dekat dengan rumah penduduk dan perkantoran, sehingga berisiko terjadinya gangguan lingkungan seperti kebisingan, bahaya kebakaran dan pencemaran udara. Sementara itu karena latar belakang pendidikan dan pengalaman kerja bagi pekerja bengkel las yang beragam menyebabkan pengelolaan bengkel tempat kerja kurang memadai, sehingga paparan bahaya di bengkel kerja dan lingkungan mengancam keselamatan dan kesehatan kerja para pekerja las dan warga masyarakat pada umumnya.

Keselamatan kerja adalah sarana utama untuk pencegahan kecelakaan, cacat dan kematian sebagai akibat kecelakaan kerja. Kecelakaan selain menjadi hambatan langsung, juga merugikan secara tidak langsung yakni kerusakan mesin dan peralatan kerja, terhentinya proses produksi untuk beberapa saat, kerusakan pada lingkungan kerja, dan lain-lain. (Suma'mur, 1985)

Tujuan keselamatan kerja adalah untuk melindungi tenaga kerja atas hak keselamatannya dalam melakukan pekerjaan untuk kesejahteraan hidup dan meningkatkan produksi serta produktivitas masyarakat, menjamin keselamatan setiap orang lain yang berada ditempat kerja serta menjamin sumber produksi dipelihara dan dipergunakan secara aman dan efisien (Suma'mur, 1985). Untuk mencapai tujuan keselamatan kerja di atas, Undang-undang Nomor 1 tahun 1970 menetapkan 18 syarat mulai dari pencegahan kecelakaan sampai dengan upaya penyempurnaan pada pekerjaan dengan risiko tinggi (Tia Setiawan dan Harun, 1980).

Keselamatan dan kesehatan kerja merupakan suatu upaya untuk menekan atau mengurangi risiko kecelakaan dan penyakit akibat kerja. Tujuan penyelengaraan keselamatan dan kesehatan kerja adalah untuk melindungi tenaga kerja, menjamin keselamatan orang lain yang berada di tempat kerja dan menjaga sumber produksi agar aman dan efisien (Sumakmur,1987).

Secara umum penyebab kecelakaan di tempat kerja meliputi: kelelahan (fatigue); kondisi tempat kerja (enviromental aspects) dan pekerjaan yang tidak aman (unsafe working condition); kurangnya penguasaan pekerja terhadap pekerjaan, ditengarai penyebab awalnya (pre-cause) adalah kurangnya training; serta karakteristik pekerjaan itu sendiri (Tambunan, 2002). Selain itu juga disebabkan faktor perorangan dan faktor pekerjaaan (Rudi Suardi, 2005); kesalahan manusia dan kondisi yang tidak aman (Tasliman, 1993); faktor 
alat/mesin, faktor manusia dan faktor lingkungan (Sumantri, 1989); tidak mengetahui tata cara yang aman, tidak memenuhi persyaratan kerja dan enggan mematuhi peraturan dan persyaratan kerja (Silalahi, 1985).

Adapun risiko bahaya yang mengancam tenaga kerja di tempat kerja terdiri dari : bahaya fisik (kebisingan, penerangan, tata udara), bahaya biologi, bahaya kimia dan bahan berbahaya lainnya serta risiko psikologis (Sumakmur,1987), yang kesemuanya memerlukan manajemen bahaya (hazard management) melalui lima prinsip pengendalian bahaya yang bisa digunakan secara bertingkat/bersamasama untuk mengurangi/menghilangkan tingkat bahaya, yaitu: penggantian dikenal sebagai engineering control; pemisahan; ventilasi; pengendalian administratif; perlengkapan perlindungan personel.

Mencermati permasalahan tersebut di atas, sangatlah penting dan mendesak untuk melatih para pekerja agar mampu mengelola bengkel mereka agar memenuhi kaidah-kaidah keselamatan dan kesehatan kerja. Hal ini dimaksudkan agar selama bekerja para pekerja bengkel tetap dalam kondisi selamat dan sehat, terhindar dari berbagai bahaya, yang pada muaranya mampu berkarya dan meningkatkan produktifit as. Pekerja las menjadi sasaran pelatihan yang utama mengingat latar belakang sebagian perkerja. S ehingga kondisi keselamatan dan kesehatan kerjapun menjadi salah satu tanggung jawab yang harus dipikul oleh para mereka.

Adapun permasalahan yang ada dapat diidentifikasikan dalam dua kelompok besar, yaitu metode pengelasan yang benar pada las SMAW, masalah keselamatan dan kesehatan kerja yang berasal dari faktor manusia beserta masalah karena faktor kondisi tempat kerja.

Oleh karena itu program pengabdian pada masyarakat ini dirumuskan menjadi dua. Pertama memahami metode las yang benar pada SMAW serta pengetahuan, wawasan dan sikap yang harus dimiliki oleh pekerja agar dapat bekerja dengan selamat dan sehat serta meningkat produktifitasnya. Kedua bagaimanakah cara pengendalian bahaya di tempat kerja yang harus dikuasai oleh para guru agar selama bekerja dapat terhindar dari risiko bahaya.

\section{METODE PELAKSANAAN}

Adapun permasalahan yang ada dapat diidentifikasikan dalam dua kelompok besar, yaitu metode pengelasan yang benar pada las SMAW, masalah keselamatan dan kesehatan kerja yang berasal dari faktor manusia beserta masalah karena faktor kondisi tempat kerja.

Oleh karena itu program pengabdian pada masyarakat ini dirumuskan menjadi dua. Pertama memahami metode las yang benar pada SMAW serta pengetahuan, wawasan dan sikap yang harus dimiliki oleh pekerja agar dapat bekerja dengan selamat dan sehat serta meningkat produktifitasnya. Kedua bagaimanakah cara pengendalian bahaya di tempat kerja yang harus dikuasai oleh para guru agar selama bekerja dapat terhindar dari risiko bahaya.

Sasaran kegiatan ini adalah para pekerja pengelola bengkel las dari sekitaran kota Banjarmasin, Jumlah peserta pelatihan direncanakan sejumlah 1015 orang.

Untuk menyelesaikan permasalahan seperti di atas dan guna mendukung efisiensi dan efektifitas program pengabdian kepada masyarakat ini, maka diajukan kerangka pemecahan masalah yang meliputi empat hal. 
1. Pelatih dipersyaratkan memiliki kompetensi teoritis dan praktis yang memadai dalam hal proses Pengelasan SMAW beserta Keselamatan dan Kesehatan Kerja, serta mampu menerapkan dalam persoalan di bengkel tempat mereka bekerja.

2. Persiapan pelaksanaan program harus dilakukan secara menyeluruh, terutama menyangkut materi pelatihan yang berupa: materi dan makalah tentang pengelasan SMAW, keselamatan dan kesehatan kerja; model-model perilaku dan sikap yang sesuai dan memenuhi kaidah-kaidah keselamatan dan kesehatan kerja; media pembelajaran yang komunikatif dan menarik bagi peserta; materi pelatihan secara lengkap harus sudah diberikan kepada peserta pelatihan sejak awal pelatihan dilaksanakan.

3. Tim menyiapkan dan melaksanakan pendampingan program Pelatihan, sehingga kemajuan pencapaian tujuan pelatihan dapat termonitor, dan tim melakukan perbaikan bila terdapat hambatan dalam pelaksanaan pelatihan. Evaluasi program dilaksanakan secara menyeluruh, meliputi: materi, pelatih, peserta dan penyelenggaraan.

4. Metode yang digunakan pada kegiatan ini antara lain ceramah, tanya jawab, demonstrasi, tutorial, tugas dan observasi terhadap kemampuan peserta pelatihan dalam penerapan kaidah-kaidah keselamatan dan kesehatan kerja di bengkel tempat kerjanya.

\section{HASIL DAN LUARAN}

Adapun pelaksanaan kegiatan pada hari Kamis s.d. Sabtu tanggal 18 Juli s.d. 20 juli 2019 bertempat di bengkel Teknik Mesin, Politeknik Negeri Banjarmasin. Waktu kegiatan yang direncanakan dilaksanakan saat kegiatan perkuliahan ditiadakan saat ujian akhir semester dikarenakan dosen dan peserta yang mempunyai waktu kosong tetapi karena berbagai kendala kegiatan baru dapat dilaksanakan diwaktu selesai ujian akhir semester di mana dosen sudah mulai bertugas. Walaupun hal ini bukan kendala yang berarti, tetapi karena peserta yang lebih banyak bekerja diluar bersamaan kegiatan maka menyebabkan konsentrasi peserta pelatihan tidak terfokus, terutama bagi para pekerja buruh las dengan pekerjaan pesanan pelanggan yang cukup banyak. Namun demikian porsi waktu dan materi pelatihan tetap dapat terpenuhi sesuai dengan rencana yaitu selama 27 jam kegiatan.

Materi pelatihan terdiri dari Pengertian dan tujuan K3 dalam pengelasan SMAW, Identifikasi Potensi Bahaya di Tempat Kerja, Faktor-faktor Penyebab Kecelakaaan Kerja, serta perlengkapan alat pelindung diri dalam pengelasan SMAW serta pelaksanaan praktek pengelasan beserta cara penggunaan alat pelindung diri dengan baik dan benar. Struktur materi pelatihan tersebut di atas disusun secara praktis dan sederhana serta dilengkapi dengan contoh dan demonstrasi sehingga mudah dicerna. Hal ini juga mengacu kepada kebutuhan bengkel akan pentingnya jaminan keselamatan dan kesehatan kerja bagi para pekerja. Selengkapnya susunan materi pelatihan digambarkan dalam tabel berikut:

Tabel 1. Materi pelatihan

\begin{tabular}{|c|c|c|c|c|}
\hline $\mathrm{NO}$ & MATERI & WAKTU & METODE & INSTRUKTUR \\
\hline
\end{tabular}




\begin{tabular}{|c|l|c|c|c|}
\hline 1 & $\begin{array}{l}\text { Pengertian dan Tujuan Keselamatan } \\
\text { dan Kesehatan Kerja }\end{array}$ & 2 Jam & $\begin{array}{c}\text { Ceramah, } \\
\text { tanya jawab }\end{array}$ & $\begin{array}{c}\text { Anhar Khalid, S.T., } \\
\text { M.T. }\end{array}$ \\
\hline 2 & $\begin{array}{l}\text { Identifikasi Potensi Bahaya di Tempat } \\
\text { Kerja }\end{array}$ & 3 Jam & $\begin{array}{c}\text { Ceramah, } \\
\text { tanya jawab, } \\
\text { demonstrasi }\end{array}$ & $\begin{array}{c}\text { Akmal Barry, S.T., } \\
\text { M.T. }\end{array}$ \\
\hline 3 & $\begin{array}{l}\text { Zat dan Bahan Berbahaya serta Faktor- } \\
\text { faktor Penyebab Kecelakaan Kerja }\end{array}$ & 2 Jam & $\begin{array}{c}\text { Ceramah, } \\
\text { tanya jawab }\end{array}$ & $\begin{array}{c}\text { Darmansyah, S.T., } \\
\text { M.T. }\end{array}$ \\
\hline 4 & $\begin{array}{l}\text { Alat pelindung Diri } \\
\text { Pencegahan dan Pemadaman } \\
\text { Kebakaran }\end{array}$ & 2 Jam & $\begin{array}{c}\text { Ceramah, } \\
\text { tanya jawab }\end{array}$ & $\begin{array}{c}\text { Anhar Khalid, S.T., } \\
\text { M.T Y Yusuf Rizal } \\
\text { Fauzi, S.T.,M.T }\end{array}$ \\
\hline 6 & Praktek pengelasan SMAW & $\begin{array}{c}\text { Ceramah, } \\
\text { tanya jawab, } \\
\text { demonstrasi }\end{array}$ & $\begin{array}{c}\text { Ceramah, } \\
\text { Saberani M.T } \\
\text { penugasan }\end{array}$ & $\begin{array}{c}\text { Anhar Khalid, S.T., } \\
\text { M.T \& Yusuf Rizal } \\
\text { Fauzi,S.T.,M.T }\end{array}$ \\
\hline
\end{tabular}

\section{KESIMPULAN DAN SARAN}

1. peserta dapat memahami dan berperilaku pentingnya $\mathrm{K} 3$, melakukan pencegahan kecelakaan kerja, mengelola bahan-bahan beracun berbahaya dan penanggulangannya, menggunakan alat pelindung diri, serta melakukan pencegahan dan pemadaman kebakaran, serta mampu menyusun program pengendalian K3 di bengkel/lab sekolah. Kesimpulan kedua adalah peserta pelatihan dapat memetik berbagai manfaat dari wawasan, pemahaman dan kemampuan K3 untuk pelaksanaan bekerja dibengkel masing- masing, yaitu sikap bekerja yang selamat dan sehat sehingga meningkatkan produktifitas kerja. Peningkatan produktifitas dalam pengelasan sesuai standarisasi pada muaranya adalah meningkatkan kemampuan para pekerja las.

2. kedua adalah peserta pelatihan dapat memetik berbagai manfaat dari wawasan, pemahaman dan kemampuan K3 untuk pelaksanaan bekerja dibengkel masing-masing, yaitu sikap bekerja yang selamat dan sehat sehingga meningkatkan produktifitas kerja. Peningkatan produktifitas dalam pengelasan sesuai standarisasi pada muaranya adalah meningkatkan kemampuan para pekerja las.

\section{DAFTAR PUSTAKA}

Depkes, 2001, Prinsip Dasar Kesehatan Kerja. Diambil pada tanggal 21 November 2019, <http://www.depkes.go.id/index.php?option= articles\&task=viewarticle \&artid=61\&Itemid=3>

Tasliman, H.A., 1993. Keselamatan dan Kesehatan Kerja (Bahan Ajar). Yogyakarta: UNY. 
Setiawan, T., 1980. Kesehatan Kerja dan Tata Laksana Bengkel. Jakarta: Departemen Pendidikan dan Kebudayaan..

Suma'mur, P.K., 2009. Higiene perusahaan dan kesehatan kerja (HIPERKES). 